\title{
Os assistentes sociais e a luta por melhores condições de trabalho: apontamentos sobre a jornada semanal de $\mathbf{3 0}$ horas
}

\author{
The Social Workers and the struggle for better working conditions: notes about the \\ workweek of 30 hours
}

\author{
Juliana Tisseu Rocha * \\ Luciane Francieli Zorzetti Maroneze ${ }^{* *}$
}

\begin{abstract}
Resumo:
O objetivo do estudo apresentado neste artigo foi analisar como se configurou o processo de luta dos Assistentes Sociais no tocante à jornada semanal de trinta horas, tendo por base as transformações globais impulsionadas pela reorganização capitalista que incide no campo de trabalho, acirrando as relações de exploração e de precarização. Trata-se de um estudo de caráter teórico que se fundamenta na produção de autores que vêm discutindo a temática em questão. Para tal, buscou-se ancoragem no método dialético, que permite compreender a problemática como parte da totalidade histórica da vida material na qual se constitui e se reproduz. A abordagem das questões pertinentes foi realizada em articulação com o cenário histórico de referência, com as transformações sociais decorrentes da crise estrutural do sistema mundial do capital, em sua fase contemporanea, e com as soluções encaminhadas pela ordem hegemônica para combater a crise, as quais vêm impondo novas exigências aos trabalhadores, incluindo, aqui, os assistentes sociais. A partir da pesquisa, conclui-se que a aprovação da Lei das 30 horas - Lei no 12.317/2010 - foi possibilitada graças à articulação política das entidades representativas em conjunto com os profissionais, porém, constata-se que há outras lutas a serem travadas por melhores condições de trabalho e de vida.
\end{abstract}

Palavras-chave: Trabalho. Precarização do trabalho. Assistente social. Jornada semanal de trinta horas.

\begin{abstract}
:
The aim of the study presented in this article was to analyze how was the setting of the struggle process of the social workers in relation of the 30 hours' workweek, having as a base the global transformations driven by the capitalist reorganization that focuses on the work field, intensifying the relations of exploration and precariousness. It is a study of theoretical character that is founded on the production of authors that discuss the theme in the question. To this end, we tried to anchor in the dialectical method, that allows the understanding of the problematic as part of the historical totality of the material life in whit it is constitute and reproduced. The approach of the relevant issues was held in conjunction with the historical reference scenario, with the social transformations arising from the structural crises of the global capitalism system in its contemporary phase, and the solutions forwarded by the hegemonic order to combat the crisis, which comes imposing new demands to the workers,
\end{abstract}

\footnotetext{
* Assistente Social pela UNESPAR/Campus de Apucarana - E-mail: juliana.tr@hotmail.com

** Professora do Curso de Serviço Social da UNESPAR/Campus Apucarana. Mestre em Educação pela Universidade Estadual de Maringá. E-mail: lucianemaroneze@gmail.com
} 
including in here the social workers. Therefrom the research concludes that the sanction of the 30-hour law - law no 12.317/2010 - It was made possible thanks to the political articulation of representative bodies together with the professionals, however, it notes that there are other struggles to be deal with for better work and life conditions.

Key words: Work. Work precariousness. Social worker. Workweek of thirty hours.

\section{Introdução}

A discussão sobre a conquista das 30 horas semanais pelos profissionais de Serviço Social não pode ser interpretada como algo isolado, desconectado de uma realidade concreta, pois as condições e as relações de trabalho só podem ser analisadas a partir de um contexto histórico. É preciso compreender que essa conquista aconteceu em um período de profundas mudanças no cenário mundial e nacional no que se refere à reorganização do sistema capitalista, onde as redefinições do trabalho atingem a totalidade da "classe que vive do trabalho (ANTUNES, 2007).

Nessa discussão, que se articula com questões sociais, políticas e econômicas, relacionadas às mudanças no mundo do trabalho, compreende-se o movimento de luta dos assistentes sociais pela aprovação da "Lei das 30 horas" (BRASIL, 2010) como expressão da organização política de uma categoria profissional que, na dinâmica de reorganização capitalista, tem seus direitos alijados.

Para a organização metodológica deste estudo, buscou-se, em um primeiro momento, situar as mudanças ocorridas na fase contemporânea do capital, sobretudo, sua reconfiguração frente à conjuntura de crises e as tendências que tornam este sistema ainda mais nocivo e perverso à reprodução da vida social. Em um segundo momento, desenvolveu-se uma discussão sobre o processo de luta dos assistentes sociais pela jornada de 30 horas semanais, num cenário de intensas mudanças no mundo do trabalho.

\section{As Novas Conformações do Trabalho na Contemporaneidade}

Em sua história, o capitalismo passou por uma sucessão de crises econômicas que interferiram, mundialmente, nas áreas política, econômica e social, determinando um novo modo de vida social, com impactos nocivos à classe trabalhadora. Este estudo tem como foco a complexidade da crise estrutural do capital, que se iniciou nos anos de 1970 e acabou 
por estabelecer uma nova etapa de desenvolvimento capitalista, capaz de exercer maior controle e domínio sobre a produção e a força de trabalho.

Como salientam Montaño e Duriguetto (2011, p. 183, grifo do autor), a

[...] atual crise é estrutural do sistema capitalista, e tem como raiz profunda o excesso de capacidade de produção que não encontra retorno nas vendas, o que, no início dos anos 1970, leva a uma forte queda da taxa de lucro, derivando assim em diversas manifestações e crises particulares.

O capital é movido pela busca de lucros e, quando não obtém os lucros almejados, passa a buscar caminhos que possam reverter tal situação. Alves (2013) destaca que a crise pode significar riscos, bem como, oportunidades históricas, visto que o capital se renova e se expande por meio das crises. Nesse sentido, Netto e Braz (2008) salientam que:

\footnotetext{
A análise teórica e histórica do MPC comprova que a crise não é um acidente de percurso, não é aleatória, não é algo independente do movimento do capital. Nem é uma enfermidade, uma anomalia ou uma excepcionalidade que pode ser suprimida no capitalismo. [...] a crise é constitutiva do capitalismo: não existiu, não existe e não existirá capitalismo sem crise (NETTO; BRAZ, 2008, p. 157, grifo do autor).
}

De acordo com Montaño e Duriguetto (2011, p. 193), para o enfrentamento da crise, o capital articula algumas estratégias que podem ser descritas a partir de três pilares: "a ofensiva do Estado contra o trabalho e suas formas de organização e lutas; a reestruturação produtiva; e a (contra) reforma do Estado". Por outro lado, Netto e Braz (2008) apontam a reorganização do capital e o enfrentamento da crise a partir do seguinte tripé: reestruturação produtiva, financeirização e ideologia neoliberal.

O capital abandona a modalidade de acumulação denominada rígida, própria do taylorismo-fordismo, e adere à acumulação flexível. Trata-se de uma nova fase, denominada de "mundialização do capital" (CHESNAIS, 1995), que compreende o processo de financeirização, que decorre, em parte, de mudanças na esfera financeira. Além disso, essa nova fase resulta da superacumulação e da queda das taxas de lucros dos investimentos na produção e no comércio, que acaba por gerar um montante fabuloso de capital, disponibilizado sob a forma de capital-dinheiro ou capital monetário.

De acordo com Montaño e Duriguetto (2011, p. 186), o "capital-dinheiro é remunerado através de juros, (bancos, companhias de seguros, fundos de pensões) e não 
é investido na produção, passando a construir a fonte crescente de riqueza dos capitalistas rentistas."

As implicações da fase de mundialização do capital recaem, principalmente, sobre a “classe que vive do trabalho" (ANTUNES, 2007), pois, segundo lamamoto (2008, p. 143), "os investimentos especulativos são favorecidos em detrimento da produção, o que se encontra na raiz da redução dos níveis de emprego, do agravamento da questão social e da regressão das políticas sociais públicas." Nota-se que o trabalhador é duplamente vitimizado, pois passar a sofrer com a flexibilização nas relações de trabalho e a redução dos níveis de emprego, uma vez que há maior investimento no setor financeiro, como também, com a ausência do Estado nos gastos públicos.

Ao vender sua força de trabalho, o assistente social encontra-se inserido nesse contexto. Nos espaços ocupacionais diversificados no qual atua, cujas demandas sociais advêm das relações contraditórias entre capital e trabalho, o mesmo é desafiado cotidianamente, visto que, enquanto trabalhador assalariado, encontra-se inserido no processo de precarização e, ao mesmo tempo, atua na defesa dos direitos frente o Estado que prioriza os lucros do capital fictício.

Netto e Braz (2008) ressaltam que as finanças passaram a construir o sistema nervoso do capitalismo e que, a partir da financeirização, é possível compreender a questão da dívida externa dos países periféricos e as propostas de "ajuste" de suas economias, que são monitoradas por agências internacionais, tais como o Banco Mundial e o Fundo Monetário Internacional.

Evidencia-se, assim, que as propostas de "ajustes" recomendam cortar gastos por meio de privatizações, o significa dizer que, por meio da privatização, grupos monopolistas e oligarquias financeiros passam a ganhar, em detrimento do investimento em gastos sociais. Sobre isso, Netto e Braz (2008, p. 235, grifo do autor) salientam que "os países dependentes e periféricos tornaram-se exportadores de capital para os países centrais", isto é, trata-se de uma hierarquia de poderes, onde o mais forte explora o mais fraco.

Para introduzir mudanças na base produtiva, torna-se necessária uma reformulação do pensamento ideológico. O capital, juntamente com a financeirização, utiliza-se do ressurgimento do neoliberalismo na década de 1970. A mudança estrutural-histórica do capitalismo tem propiciado o sucesso da ideologia neoliberal, além disso, as crises e as 
dificuldades estruturais são fundamentais para o capitalismo, que encontra nelas soluções pragmáticas, como, por exemplo, o ressurgimento dessa ideologia que, por sua vez "tratase de um corpo de doutrina coerente, autoconsciente, militante, lucidamente decidido a transformar todo o mundo à sua imagem, em sua ambição estrutural e sua extensão internacional" (ANDERSON, 1995, p. 22).

Segundo Petras (1997), o neoliberalismo apresenta semelhanças e diferenças em relação ao liberalismo, pois ambos se posicionam contra regulamentações de caráter trabalhista, e, em sentido contrário, favorecem a chamada "auto-regulamentação" do mercado. O autor faz referência ao slogan desse princípio, ou seja, o melhor governo é aquele que governa com menos. Nesse sentido, autores como Montaño e Duriguetto (2011) ressaltam que a ofensiva neoliberal tem seus pilares fundados na minimização do Estado e na liberdade de mercado.

A minimização do Estado de Bem-Estar Social permite ao neoliberalismo converter trabalhadores assalariados em "informais" e/ou autônomos, de forma que se enfraqueça o movimento trabalhista e se exclua a legislação social (PETRAS, 1997), o que, por sua vez, caracteriza-se como um verdadeiro ataque às formas de organização política dos trabalhadores.

Esse movimento ideológico ocorre em escala mundial, como o capitalismo jamais havia produzido no passado. Contudo, vale ressaltar que, embora o capitalismo tenha, insistentemente, buscando tais mudanças, os resultados foram inesperados, conforme expõe Anderson:

[...] Economicamente, o neoliberalismo fracassou, não conseguindo nenhuma revitalização básica do capitalismo avançado. Socialmente, ao contrário, o neoliberalismo conseguiu muitos dos seus objetivos, criando sociedades marcadamente mais desiguais, embora não tão desestatizadas como queria. Política e ideologicamente, todavia, o neoliberalismo alcançou êxito num grau com o qual seus fundadores provavelmente jamais sonharam, disseminando a simples ideia de que não há alternativas para seus princípios, que todos, seja confessando ou negando, têm de adaptar-se a suas normas (ANDERSON, 1995, p. 23).

Com base em tais argumentos, nota-se uma tendência à naturalização do pensamento neoliberal, pois a ideia principal era a de que os países que aderissem à política neoliberal se desenvolveriam financeiramente, isto é, a de que tal posicionamento promoveria aumento na economia do país, trazendo desenvolvimento e modernidade, 
principalmente, aos países periféricos, contudo, não foi isso que ocorreu. Os países centrais, disseminadores da ideia, não conseguiram alterar os índices de recessão e baixo crescimento, o que acabou por ocasionar amplos efeitos, como o aumento do desemprego, a redução dos salários e a desmobilização dos trabalhadores.

Com o processo de mundialização do capital, houve a transição da modalidade de acumulação rígida para a de acumulação flexível. Isso quer dizer que, anteriormente, o modo de produção, que era direcionado pelo modelo fordista-taylorista, passa a dividir espaço com um novo modelo de produção, conhecido como toyotista, considerado por Alves (1999) como um momento predominante do processo de reestruturação produtiva. As alterações no modelo de acumulação expressam uma ofensiva do capital na produção conhecida como reestruturação produtiva, que, por sua vez, tende a debilitar o mundo do trabalho. Assim:

[...] A reestruturação produtiva afeta radicalmente a organização dos processos de trabalho: o consumo e gestão da força de trabalho, as condições e relações de trabalho, assim como o conteúdo do próprio trabalho. Envolve a intensificação do trabalho e a ampliação da jornada, a redução dos postos de trabalho e a precarização das condições e dos direitos do trabalho. Reduz-se a demanda de trabalho vivo ante o trabalho passado incorporado nos meios de produção, com elevação da composição técnica e de valor do capital, ampliando o desemprego estrutural (IAMAMOTO, 2008, p. 143-144).

Ressalta-se que a nova ofensiva do capital na produção não é impulsionada somente pela tecnologia, mas também por um conjunto de determinações tecnológicas e políticas, caracterizadas pelo ideário neoliberal que, por sua vez, subordina os direitos sociais à lógica financeira. Assim, além das alterações no modo de produção, ocorre um enfraquecimento, principalmente, dos sindicatos.

Netto e Braz (2008) salientam que a reestruturação produtiva é uma intensiva incorporação de tecnologias resultantes de avanços técnico-científicos, o que desencadeia a substituição do trabalho vivo pelo morto. Tais alterações no modo de produção têm gerado algumas implicações: a primeira diz respeito ao trabalhador coletivo, que se faz cada vez mais presente; a segunda refere-se às novas condições que envolvem, diretamente, os trabalhadores da produção, determinando que eles sejam mais qualificados; a terceira refere-se à gestão dessa força de trabalho, visto que é nesse momento que o despotismo industrial surge sob formas diversificadas, pois passa a se 
utilizar de estratégias que abrangem a participação e o envolvimento dos trabalhadores, tornando possível a valorização da comunicação e a redução de hierarquias mediante a utilização de equipes de trabalho.

Nesse contexto, Netto e Braz (2008, p. 217) chamam a atenção para o fato de que a ofensiva do capital ao trabalho se traduz pela manipulação da subjetividade dos trabalhadores.

O capital empenha-se em quebrar a consciência de classe dos trabalhadores: utiliza-se o discurso de que a empresa é a sua "casa" e que eles devem vincular o seu êxito pessoal ao êxito da empresa; não por acaso, os capitalistas já não se referem a eles como "operários" ou "empregados" - agora, são "colaboradores", "cooperadores", "associados" etc..

Ao ter sua subjetividade capturada, o trabalhador perde o controle de sua vida, o que gera alienação, que, por sua vez, é indissociável do trabalho assalariado. Nesse sentido, Antunes e Alves (2004, p. 348, grifo do autor) ressaltam que esta condição "assume a forma de perda de sua própria unidade: trabalho e lazer, meios e fins, vida pública e vida privada, entre outras formas de disjunção dos elementos de unidade presentes na sociedade do trabalho." O trabalho faz do indivíduo um ser social, contudo, as reconfigurações do sistema de produção fazem com que este tenha sua identidade social camuflada pelos interesses capitalistas.

Nota-se que o assistente social não se difere dos outros trabalhadores que têm sua subjetividade "controlada" pela lógica do capital. Percebe-se ainda que, tanto no âmbito público como no privado ou no terceiro setor, o profissional não está imune às várias formas de alienação, justificadas, supostamente, no discurso da eficiência, competência, responsabilidade e sensibilidade.

Nessa lógica, a reestruturação produtiva trouxe novas dimensões ao trabalho, alterando as funções desempenhadas e a rotina do trabalhador. Percebe-se que o assistente social se encontra inserido na totalidade dos trabalhadores, que vendem sua força de trabalho, sofrem a intensificação das tarefas e se deparam com dificuldades no exercício profissional resultantes de: baixa remuneração; redução de pessoal; carga horária excessiva; rotatividade no emprego; instabilidade e insegurança; contratos de trabalho 
temporários; inserção do profissional em duas ou mais políticas sociais, o que caracteriza o pluriemprego; ausência de políticas de capacitação profissional, entre outros fatores.

Assim, é no contexto da reestruturação produtiva que se pode compreender o surgimento de "um novo e precário mundo do trabalho" (ALVES, 2013). Todavia, vale ressaltar que a reorganização do capitalismo, no Brasil, emerge com o ajuste neoliberal e a reestruturação produtiva na década de 1990 (ALVES, 2013). Nesse sentido, Boito Júnior (1999) expõe que:

[...] a política neoliberal não produz efeitos idênticos em todos os países ou regiões. Uma distinção básica deve ser estabelecida entre o neoliberalismo nos países centrais e o neoliberalismo nos países periféricos. Constitui um erro, que tem sido cometido por parte do pensamento crítico brasileiro, sugerir que o neoliberalismo tem provocado danos iguais aos trabalhadores em todas as partes do mundo (BOITO, 1999, p. 30-31).

Como os impactos são diferentes em países centrais e periféricos, cabe ressaltar que, no Brasil, estes foram ainda mais graves, uma vez que não se chegou a vivenciar um Estado de Bem-Estar Social em sua completude, conforme Oliveira (1998 apud IAMAMOTTO, 2008). Desta forma, mesmo que implantada tardiamente, a ideologia neoliberal não alcançou seu objetivo no aspecto econômico e, assim, o processo de reorganização produziu resultados mais intensos.

Cabe ressaltar que a ofensiva do capital, que ocorre por meio da reestruturação produtiva, tem como um de seus focos a precarização do trabalho. Segundo Alves (2013), essa precarização ocorre em dimensão radical, no sentido de ir até às raízes, sendo que a raiz é o próprio homem que trabalha.

Como a lógica é garantir maior liberdade ao mercado (empresas), a reestruturação produtiva, no Brasil, trouxe mudanças significativas na legislação trabalhista, ou seja, as empresas passaram a admitir e demitir seus trabalhadores conforme a necessidade de mercado, isto é, de produção. Nesse contexto, considera-se a terceirização como a principal modalidade de flexibilização do trabalho, pois ela possibilita ao capital a liberdade de gerenciar e dominar a força de trabalho, transferindo a responsabilidade trabalhista a um terceiro, ou seja, é uma estratégia utilizada para reduzir os custos.

Em mundo dominado pelo valor de troca, o assistente social acaba por se inserir em uma relação de compra e venda e passa a ter sua força de trabalho mercantilizada, o que 
desencadeia algumas implicações, tais como: adequação do trabalho profissional às exigências do mercado, ou seja, sua força de trabalho é tensionada às exigências dos empregadores; e inserção nas diversas modalidades de contratação, uma vez que depende da venda de sua força de trabalho para sobreviver.

A conquista das 30 horas semanais, as lutas encampadas pelo CFESS e pelo CRESS para a definição de um piso salarial, a contratação por meio de concursos, entre outras reivindicações, expressam a defesa dos profissionais pelos seus direitos, como também, uma oposição à lógica capitalista, que tende, cada vez mais, a deteriorar os direitos trabalhistas. Desse modo, são reivindicações por melhoria das condições de trabalho, pois o movimento do capital vem na contramão dos direitos conquistados, historicamente, pelos trabalhadores.

\section{A Luta pela Jornada Semanal de $\mathbf{3 0}$ Horas}

As discussões acerca das condições de trabalho dos profissionais de Serviço Social têm sido ampliadas desde o início deste século. Conforme alguns autores, como Boschetti (2011), Raichelis (2011), Santos (2010), a luta e a conquista dos profissionais pela jornada semanal de 30 horas, sem redução salarial, têm ganhado evidência nos debates.

lamamoto (2008) destaca que, ao se fazer uma análise sobre o trabalho do assistente social, deve-se levar em consideração os dilemas vividos pelo conjunto dos trabalhadores, incluindo suas lutas, bem como, as perdas de conquistas históricas. Segundo a autora, como a força de trabalho é uma mercadoria, esta só pode ser transformada quando:

[...] aliada aos meios necessários à sua realização, grande parte dos quais se encontra monopolizado pelos empregadores: recursos financeiros, materiais e humanos necessários à realização desse trabalho concreto, que supõe programas, projetos e atendimentos diretos previstos pelas políticas institucionais (IAMAMOTO, 2008, p. 421).

Nota-se que, ao vender sua força de trabalho, com o fim de atender uma necessidade social, os assistentes sociais se enquadram no que se chama de autonomia relativa, pois os empregadores, do setor público, privado e terceiro setor, articulam um conjunto de ações que acabam por limitar a ação profissional. Verifica-se, também, a existência de uma tensão no que se refere ao projeto profissional, uma vez que os assistentes sociais estão 
submetidos ao estatuto de trabalhador assalariado, sujeitos, portanto, às relações de compra e venda da força de trabalho.

Raichelis (2011, p. 426, grifo nosso) afirma que é frequente "o assistente social analisar (e indignar-se) frente à exploração e ao desgaste a que são submetidos os trabalhadores assalariados, mas estabelecendo com estes uma relação de exterioridade $\mathbf{e}$ de não pertencimento enquanto um segmento desta mesma classe."

Assim, os profissionais de serviço social têm enfrentado desafios que tendem a despolitizar e fragmentar as formas de organização política, o que leva muitos deles a não se reconhecerem como pertencentes à "classe que vive do trabalho", embora sua atuação seja, essencialmente, voltada ao atendimento das necessidades sociais dessa classe. Em tempos de implementação de políticas neoliberais, exacerbam-se: as orientações ideológicas com predomínio de atitudes individuais; o pensamento conservador; e as práticas meritocráticas e racionalizadoras que interferem na organização política dos assistentes sociais.

Embora a profissão tenha salvaguardas jurídico-políticas, os profissionais sofrem com a violação das leis trabalhistas, visto que, no mesmo campo onde, timidamente, são implementadas iniciativas voltadas à ampliação dos direitos, há, também, as que enfraquecem e reduzem, cada vez mais, a proteção social dos trabalhadores.

Santos (2010) evidencia a ação política do Conselho Federal de Serviço Social (CFESS) na defesa das condições de trabalho dos assistentes sociais. Conforme a autora, a principal e, possivelmente, histórica ação, que visou a melhorias nas condições de trabalho dos assistentes sociais, foi articulada pelo conjunto: Conselho Federal de Serviço Social (CFESS); Conselho Regional de Serviço Social (CRESS); Associação Brasileira de Ensino e Pesquisa em Serviço Social (ABEPSS); e Executiva Nacional dos Estudantes de Serviço Social (ENESSO), que, no uso de suas atribuições legais e regimentais, engendraram uma luta em conjunto com os assistentes sociais do Brasil, em um Ato Público em defesa da redução da carga horária.

O Conjunto CFESS-CRESS acompanhou toda a tramitação do Projeto de Lei que estabelece jornada semanal de 30 horas aos assistentes sociais, sem redução salarial. Este processo se iniciou em 2007, na Câmara dos Deputados, com PL 1.890/2007, tendo como autor o Deputado Mauro Nazif (PSB/RO). É importante ressaltar que antes de se manifestar 
favorável ao PL, representantes do CFESS-CRESS e Seccionais reuniram-se em audiências com seu autor e relator, quando foi possível esclarecer algumas preocupações como, por exemplo: o risco de haver redução salarial; o risco de provocar ampliação na jornada de profissionais que exercem carga horária inferior a de 30 horas; e o risco de emendas com alterações em artigos da Lei 8.662/1993 (BRASIL, 1993), que regulamenta a profissão.

De acordo com o CFESS $(2008,2011)$, a luta por melhores condições de trabalho para os assistentes sociais é um compromisso que ressalta o esforço pelo direito ao trabalho com qualidade para todos os trabalhadores. Entretanto, a luta não demanda só carga horária, mas outras reivindicações, como: concurso público; salários compatíveis com a carga horária; planos de cargos, carreiras e remuneração em todos os espaços sócioocupacionais; e estabilidade no emprego.

Ao se engajar a luta pela aprovação do PL, o CFESS participou de inúmeras reuniões com os deputados e acompanhou mais de 20 sessões assumidas pela Comissão de Trabalho, de Administração e Serviço Público (CTASP) e pela Comissão de Constituição e Justiça e de Cidadania (CCJC), pois foram elas que analisaram o PL. Nesse momento, o CRESS e os assistentes sociais começaram a se mobilizar, por meio de envio de e-mail aos parlamentares e aos assistentes sociais do Distrito Federal, para que participassem das sessões em que o Projeto seria votado. Cabe ressaltar que foram 358 dias de tramitação na Câmara dos Deputados.

Os movimentos sociais, no decorrer da história, têm enfrentado dificuldades na luta contra as diversas formas de opressão e ampliação dos processos democráticos. Percebese que as resistências estão presentes em contextos mais recentes, sobretudo, quando estão envolvidas questões relativas à ampliação dos direitos, como a luta dos profissionais pela redução da jornada de trabalho.

Embora a Federação Nacional de Assistentes Sociais (FENAS) tenha se manifestado contra o Projeto, como discutido adiante, o mesmo foi aprovado com unanimidade na sessão da CCJC, de 20 de agosto de 2008. Os trâmites desse processo foram inúmeros e essa foi apenas uma etapa enfrentada.

Em setembro do mesmo ano, o PL foi encaminhado pela Mesa Diretora da Câmara dos Deputados (MESA) ao Senado Federal. Após a vitória na Câmara, a luta continuou por 
mais 11 meses no Senado, então com uma nova numeração: Projeto Lei da Câmara (PLC) $152 / 2008$.

Em 2009, ao retomar as articulações, o CFESS obteve informações de que a Senadora Lúcia Vânia (PSDB-GO) havia assumido a relatoria da matéria e emitido parecer favorável em 07 de abril. Na sessão da CAS, realizada em 15 de abril de 2009, compareceram representantes do CFESS e de quatro CRESS (SC, AM/RR, AL e DF), com o objetivo pressionar os senadores para a aprovação do PLC. Todavia, o PLC foi retirado de pauta devido às manifestações contrárias do FENAS. Diante do exposto, a senadora convidou representantes do CFESS e do FENAS para uma reunião no dia 16 de abril de 2009. Nessa reunião, o CFESS reafirmou sua posição favorável ao PLC 152/2008 e o FENAS, seu posicionamento contrário, alegando preocupação com os profissionais que conquistaram, por meio de acordos coletivos, carga horária inferior a 30 horas. Essa reunião possibilitou ao CFESS a oportunidade de esclarecer alguns aspectos sobre o PLC, ou seja, que o Projeto não traria prejuízo a esses profissionais, por se tratar de conquistas expressas em legislações especificas de municípios e estados.

Percebe-se que o processo foi bastante extenso. No entanto, os representantes da categoria, que à frente estavam, não desistiram da luta, ao contrário, passaram a articular, cada vez mais, os assistentes sociais e entidades representativas, além de instituições como a Associação Latino-americana de Ensino e Pesquisa em Serviço Social (ALAEITS), e a ABEPSS.

Conforme apontamentos do CFESS (2011, p. 27), "pesquisas mostram que, depois dos policiais e professores, somos uma das categorias mais expostas ao stress e riscos para a saúde." A historicidade da profissão confirma que os assistentes sociais estão sujeitos ao desgaste físico e mental, tanto quanto aos demais trabalhadores. Ao lidar com situações complexas e com políticas marcadas pela escassez de recursos, o profissional se vê em um campo minado de tensões, tendo que responder às demandas, mesmo em circunstâncias adversas.

Por sete vezes, o PLC entrou na Ordem do Dia, mas não foi apreciado. Quando entrou pela oitava vez, o plenário do Senado aprovou o Requerimento no 834, de autoria do Senador Romero Jucá, que solicitava o adiamento da discussão da matéria por trinta dias. 
É evidente que lutas implicam resistências, sobretudo quando se trata de lutas contrárias ao interesse do capital. A luta pelas 30 horas não foi diferente, uma vez que se tornou clara a resistência por parte do capital. Cabe destacar que a luta travada envolveu o coletivo, o que possibilitou o fortalecimento do movimento dos profissionais no que se refere à conquista da redução da jornada de trabalho.

Mediante as dificuldades, o CFESS buscou estratégias, entre elas, uma moção de apoio à aprovação do PLC na VII Conferência Nacional de Assistência Social, ocorrida em 2009, quando teve o documento aprovado e encaminhado ao Senado, no entanto, isto não foi suficiente. Desta forma, os profissionais do CFESS articularam uma audiência com a Ministra de Desenvolvimento Social e Combate à Fome, a assistente social Márcia Helena Carvalho Lopes, que foi realizada em 18 de maio de 2010. O CFESS solicitou apoio público à aprovação do PLC e articulações com os parlamentares para que o processo de tramitação fosse acelerado.

Como outros PLs, com natureza semelhante à do PLC 152/2008, permaneceram por mais de cinco anos sem votação, o CFESS constatou que o mesmo só seria votado sob pressão pública. Assim, o CFESS sugeriu à Comissão Organizadora do XIII Congresso Brasileiro dos Assistentes Sociais (CBAS) que fosse incluído, na programação, um dia nacional de luta em defesa dos Projetos de Lei em tramitação. As entidades organizadoras aderiram à ideia e lançaram uma carta convocatória para o XIII CBAS, ou seja, convidaram os assistentes sociais para participarem do evento, que teve como tema: "Lutas Sociais e Exercício Profissional no Contexto da Crise do Capital: Mediações e Consolidação do Projeto Ético-Político Profissional."

O convite ao Ato Público foi estendido aos movimentos sociais e aos estudantes. Agendado, primeiramente, para o dia 05 de agosto de 2010, a partir das 9:00h, foi antecipado para o dia 03 de agosto, pois o Senado concentrou uma pauta estendida de assuntos antes do recesso. O Ato Público foi articulado para pressionar o Congresso a aprovar Projetos em tramitação, tais como: PL que estabelece carga horária de 30 horas semanais, sem redução salarial; PL que define a inserção do assistente social nas escolas; PL que define o piso salarial em sete salários mínimos, entre outros.

O grande e tão esperado dia chegou e, aos poucos, as pessoas foram se aproximando e dando maior visibilidade ao movimento, que totalizou, aproximadamente, três mil 
pessoas, entre assistentes sociais, estudantes e representantes de movimentos sociais, como, por exemplo: Liga Brasileira de Lésbicas, Grupo em Defesa da Diversidade AfetivoSexual do movimento LGBT; Movimento dos Trabalhadores Sem Teto (MTST); movimento indígena; sindicatos de diversos segmentos como Sindjus-DF (trabalhadores do judiciário) e da Federação Nacional dos Sindicatos de Trabalhadores em Saúde, Previdência e Assistência Social (Fenasps). Além destes, também estavam presentes representantes da Consulta Popular e da Associação de Assistentes Sociais e Psicólogos do Tribunal de Justiça do Estado de São Paulo (TJ/SP).

A diversidade de profissionais envolvidos, nesse movimento, ampliou a força política de defesa do PLC 152/2008. É importante salientar que, além do Ato Público, foi necessário o convencimento político dos senadores para que colocassem o Projeto em pauta e o aprovassem.

\footnotetext{
Quem participou da sessão do Senado no dia 03 de agosto de 2010 jamais esquecerá as centenas de mãos dos/as assistentes sociais que se levantavam em coro silencioso e contundente para "aplaudir" cada manifestação favorável dos/as senadores/as em defesa do PLC. O silêncio não pôde ser mantido quando a presidência da mesa anunciou a aprovação unânime do PL e, apesar de ferir o protocolo, os/as assistentes sociais aplaudiram, gritaram palavras de ordem, se abraçaram, se emocionaram e comemoraram intensamente sua vitória, resultado inequívoco da mobilização coletiva organizada pelas entidades da categoria com firmeza e precisão política (CFESS, 2011, p. 98).
}

Neste momento, a conquista por melhores condições de trabalho estava a um passo da vitória, entretanto, houve necessidade de se travar outra luta, para que o Presidente da República sancionasse o PLC. O Senado Federal encaminhou o PLC aprovado ao Presidente da República em 06 de agosto de 2010, mas a sanção presidencial só ocorreu no dia 26 de agosto de 2010. Durante esse intervalo de vinte dias, a campanha "Lula, sancione o PL 30 horas" recebeu mais de 20 mil assinaturas, encaminhadas à Casa Civil da Presidência da República.

É evidente que esse foi o movimento mais importante dos últimos anos, principalmente, devido à atual conjuntura adversa à ampliação dos direitos. Contudo, a luta não terminou com a sanção presidencial, pois, na realidade, outra foi iniciada, pela aplicabilidade da Lei pelos empregadores. 
Nesse sentido, várias estratégias foram criadas para a implementação da Lei 12.317/2010, como, por exemplo: envio de correspondências do CFESS e do CRESS aos empregadores públicos e privados no âmbito federal, estadual e municipal, nas áreas da saúde e da assistência social; envio de ofício do CFESS ao Ministério Público do Trabalho (MPT), dando ciência da Lei e solicitando a fiscalização sobre sua implementação; reuniões do CFESS com o Ministério de Planejamento, Orçamento e Gestão (MPOG), Instituto Nacional do Seguro Social (INSS), Ministério da Saúde (MS) e MDS; e reuniões e audiências com governadores dos estados, prefeitos e gestores públicos estaduais e municipais. Para complementar essas estratégicas, foi criado, na página do CFESS, o "Observatório das 30 horas para os/as assistentes sociais". Houve intensificação na fiscalização por parte da Comissão de Fiscalização dos CRESS e, além disso, foram ampliadas as reuniões com os assistentes sociais para orientá-los sobre como se mobilizar.

Sabe-se que ainda há vários profissionais que não conseguiram a aplicabilidade da Lei 12.317/2010 (BRASIL, 2010), que dispõe alterações na Lei 8.662/1993 (BRASIL, 1993), no que se refere à duração do trabalho do Assistente Social em seu campo ocupacional. Cabe ressaltar que, a partir do momento em que a nova Lei foi sancionada e vigorada, todos os assistentes sociais que exercem suas atividades ainda de acordo com a Lei 8.662/1993 passaram a ter direito à jornada de trabalho de 30 horas semanais, sem redução no salário. Assim, as instituições empregadoras públicas, privadas e do terceiro setor devem se adequar à jornada de trabalho estabelecida em Lei. Os profissionais que ainda exercem carga horária superior a 30 horas devem entrar em contato com o CRESS, que irá oficiar a instituição empregadora informando sobre a Lei. No entanto, o CRESS é uma instituição de fiscalização, ou seja, ela não possui poder jurídico para exigir a aplicabilidade da Lei, somente esclarece os empregadores sobre a Lei e os assistentes sociais sobre como se articularem para que seus direitos sejam assegurados.

Curiosamente, após a aprovação da Lei 12.317/1010, tem sido comum a contratação de assistentes sociais sob outras nomenclaturas. Além disso, houve uma ampliação no que se refere à contratação de profissionais por projetos, por tarefas e por tempo determinado. Isso ocorre devido às tendências do capitalismo, assim, a conquista dos assistentes sociais pela redução da carga horária segue na contramão das exigências do mercado. 
Esse longo e exaustivo processo foi um movimento político da categoria, visto que, se as iniciativas fossem conduzidas isoladamente, esse Projeto de Lei continuaria engavetado, assim como o PL 3688/2000 (conhecido como PL Educação) e o PL 4022/2008, que dispõe sobre o piso salarial dos assistentes sociais, que continuam em trâmite.

Embora essa conquista não tenha sido efetivada em sua totalidade, pois ainda há vários profissionais que exercem carga horária superior a 30 horas semanais, o movimento pela garantia desse direito e de outros que possibilitam a melhoria das condições de trabalho deve ser algo permanente no cotidiano dos assistentes sociais que atuam em diversos espaços ocupacionais e possuem diferentes relações de trabalho.

\section{Considerações finais}

Os apontamentos apresentados nesta pesquisa estão longe de esgotar as complexas questões contidas no mundo do trabalho, entretanto, possibilitaram o conhecimento sobre os fenômenos sócio-históricos do capitalismo, que repercutem, cotidianamente, nas relações de trabalho.

Percebe-se que a acumulação flexível, como parte da reorganização do capital, desencadeia maior concentração de riqueza em razão do aumento das desigualdades sociais. Além deste agravante, a reorganização traz consigo mudanças nas relações sociais. Desta forma, a classe trabalhadora passa a ter sua força de trabalho cada vez mais explorada e seus direitos, reduzidos.

É importante salientar que o processo de reestruturação produtiva perpassa o setor econômico e atinge outros âmbitos da vida social. Os novos aspectos trazidos à produção propõem, no plano ideológico, político e cultural, a individualidade, a ampliação da desigualdade e, principalmente, a segmentação da classe trabalhadora.

São inúmeros os impactos da reorganização do sistema capitalista sobre a classe trabalhadora, pois sua nova forma de gestão amplia a precarização do mundo do trabalho. Assim, a classe que vive do trabalho (ANTUNES, 2007) passa a ter sua subjetividade capturada. Inserido na totalidade dos trabalhadores, o assistente social também sofre interferências advindas da reorganização do capital. Além disso, esse profissional, ao vender sua força de trabalho, está sujeito à alienação, como qualquer outro trabalhador, bem como, às várias formas de precarização. 
A desregulamentação do trabalho trouxe, também, a fragmentação dos trabalhadores, o que interfere nas formas de organização política. Contudo, a luta pela redução da jornada de trabalho, que os assistentes sociais iniciaram em 2007 e redundou em vitória em 2010, evidencia que é possível fazer alterações, visando a melhores condições de trabalho e de vida. Entretanto, esse movimento só alcançou a "vitória" devido à articulação política da categoria.

Cabe ressaltar que essa luta dos assistentes sociais deve ser compreendida no conjunto de luta da classe trabalhadora, pois é evidente que a organização coletiva dos trabalhadores é um movimento necessário para se fazer frente às diversas formas de violação dos direitos.

\section{Referências}

ALVES, G. Dimensões da precarização do trabalho: ensaios de sociologia do trabalho. Bauru: Canal 6, 2013. (Projeto editorial praxis).

ALVES, G. Racionalidade (e desrazão) do Toyotismo. In: Trabalho e mundialização do capital: a nova degradação do trabalho na era da globalização. 2. ed. Londrina: Praxis, 1999. p. 109-136.

ANDERSON, P. Balanço do neoliberalismo. In: SADER, E.; GENTILI, P. (Org.). Pósneoliberalismo: as políticas sociais e o estado democrático. Rio de Janeiro: Paz e Terra, 1995. p. 9-23.

ANTUNES, R. Dimensões da precarização estrutural do trabalho. In: DRUCK, G.; FRANCO, T. (Org.). A perda da razão social do trabalho: terceirização e precarização. São Paulo: Boitempo, 2007. p. 13-22.

ANTUNES, R.; ALVES, G. As mutações no mundo do trabalho na era da mundialização do capital. Educação e Sociedade, Campinas, v. 25, n. 87, p. 335-351, maio/ago. 2004.

BOITO JÚNIOR, Armando. Neoliberalismo e burguesia. In: . Política neoliberal e sindicalismo no Brasil. São Paulo: Xamã, 1999. p. 23-76.

BOSCHETTI, I. Condições de trabalho e a luta dos(as) assistentes sociais pela jornada semanal de 30 horas. Serviço Social \& Sociedade, São Paulo, n. 107, p. 557-584, 2011.

BRASIL. Lei n. 8.662, de 7 de junho de 1993. Dispõe sobre a profissão de assistente social, já com a alteração trazida pela Lei no 12.317, de 26 de agosto de 2010. Disponível em: <http://www.planalto.gov.br/ccivil_03/leis/L8662.htm>. Acesso em: 5 jun. 2015.

BRASIL. Lei no 12.317, de 26 de agosto de 2010. Acrescenta dispositivo à Lei no 8.662, de 7 de junho de 1993, para dispor sobre a duração do trabalho do Assistente Social. Disponível em: <http://www.planalto.gov.br/ccivil_03/_Ato2007-2010/2010/Lei/L12317.htm>. Acesso em: 2 maio 2015. 
CFESS. Conselho Federal de Serviço Social. Direito se conquista: a luta dos/as assistentes sociais pelas 30 horas semanais. Brasília: CFESS, 2008.

BRASIL. Esclarecimento sobre a implantação da jornada de 30 horas para Assistentes Sociais sem redução salarial - CFESS. Serviço Social \& Sociedade, São Paulo, n. 105, p. 188193, 2011.

CHESNAIS, F. A globalização e o curso do capitalismo de fim-de-século. Economia e Sociedade, Campinas, p. 1-30, dez. 1995.

IAMAMOTO, M. V. Capital fetiche, questão social e serviço social. In: Serviço social em tempo de capital fetiche: capital financeiro, trabalho e questão social. 2. ed. São Paulo: Cortez, 2008. p. 105-208.

MONTAÑO, C.; DURIGUETTO, M. L. A (contra) reforma do Estado no regime de acumulação flexível (pós-1973). In: Estado, classe e movimento social. 3. ed. São

Paulo: Cortez, 2011. p. 180-220.

NETTO, J. P.; BRAZ, M. As crises e as contradições do capitalismo. In: . Economia política: uma introdução crítica. 4. ed. São Paulo: Cortez, 2008. p. 156-167.

PETRAS, J. Os fundamentos do neoliberalismo. In: OURIQUES, N. D.; RAMPINELLI, W. J. (Org.). No fio da navalha: crítica às reformas neoliberais de FHC. São Paulo: Xamã, 1997. p. 15-38.

RAICHELIS, R. O assistente social como trabalhador assalariado: desafios frente às violações de seus direitos. Serviço Social \& Sociedade, São Paulo, n. 107, p. 420-437, 2011. SANTOS, S. M. M. O CFESS na defesa das condições de trabalho e do projeto ético-político profissional. Serviço Social \& Sociedade, São Paulo, n. 104, p. 695-714, 2010. 